Empirical

\title{
What Does Your Favourite Colour Say About Your Personality? Not Much
}

Qu'est-ce que votre couleur préférée dit sur votre personnalité? Pas grand-chose

\author{
Domicele Jonauskaite $^{1,2}$ (D) , Amber Gayle Thalmayer $^{1}$ (D) , Lauriane Müller ${ }^{1}$ (D) , \\ Christine Mohr ${ }^{1}$
}

[1] Institute of Psychology, University of Lausanne, Lausanne, Switzerland. [2] Faculty of Psychology, University of Vienna, Vienna, Austria.

Personality Science, 2021, Vol. 2, Article e6297, https://doi.org/10.5964/ps.6297

Received: 2021-03-25 • Accepted: 2021-11-25 • Published (VoR): 2021-12-14

Handling Editor: John F. Rauthmann, Bielefeld University, Bielefeld, Germany

Reviewing: Round 1 - Felix Schönbrodt; Anonymous \#1. Open reviews are available. [see Index of Supplementary Materials]

Corresponding Author: Domicele Jonauskaite, Faculty of Psychology, Department of Cognition, Emotion, and Methods in Psychology, Liebigasse 5, 1010 Vienna, Austria. E-mail: Domicele.Jonauskaite@univie.ac.at

Supplementary Materials: Data, Materials [see Index of Supplementary Materials]

\begin{abstract}
The claim that favourite colours reveal individuals' personalities is popular in the media yet lacks scientific support. We assessed this claim in two stages. First, we catalogued claims from six popular websites, and matched them to key Big Six/HEXACO trait terms, ultimately identifying 11 specific, systematic, testable predictions (e.g., higher Extraversion among those who prefer red, orange, yellow, pink, or turquoise). Next, we tested these predictions in terms of the Big Six personality trait scores and reports of favourite and least favourite colours from 323 Frenchspeaking participants. For every prediction (e.g., red-extraversion), we compared trait scores between participants who chose or did not choose the predicted colour using Welch's t-tests. We failed to confirm any of the 11 predictions. Further exploratory analyses (MANOVA) revealed no associations between colour preferences and personality trait. Favourite colours appear unrelated to personality, failing to support the practical utility of colour-based personality assessment.
\end{abstract}

\section{Keywords}

colour preference, 30QB6 Big Six, HEXACO, beliefs, individual differences, personality correlates, affect, crossmodal correspondences 


\section{Résumé}

L'affirmation selon laquelle les couleurs préférées révèlent la personnalité individuelle est médiatiquement populaire, mais elle manque de fondement scientifique. Nous l'avons évaluée en deux étapes. Tout d'abord, nous avons répertorié les affirmations de six sites web populaires et les avons comparées aux termes clés du Big Six/HEXACO. Cela nous a permis d'identifier 11 prédictions spécifiques, systématiques et testables. Ensuite, nous avons testé ces prédictions selon les scores de traits du Big Six et les réponses concernant les couleurs préférées et moins préférées de 323 participants francophones. Les t-tests de Welch n'ont confirmé aucune des 11 prédictions (par exemple, extraversion-rouge). D'autres analyses exploratoires (MANOVA) n'ont révélé aucune association entre les préférences de couleur et les traits de personnalité. Les couleurs préférées ne semblent pas liées à la personnalité, ne permettant pas de soutenir l'utilité pratique d'une évaluation de la personnalité basée sur les couleurs.

\section{Mots-clés}

préférence de couleur, 30QB6 Big Six, HEXACO, croyances, différences individuelles, traits de personnalité, affect, correspondances cross-modal

\section{Non-Technical Summary}

\section{What is the study's background?}

From distant history until today, many claims are made about what will reveal hidden character and personality traits. These range from your handwriting to the arrangement of the stars and planets at your time of birth. Similarly, popular media is full of claims that your personality can be revealed by your colour preferences. On websites, you can read that those who love red are "extraverted and optimistic, confident and courageous", "fiery and energetic", or have a "strong personality" while those who love blue are "conservative, reliable and trustworthy" or are "the meditative type, ... good at keeping calm and level-headed". Many of these claims are complementary across sites, while others contradict each other. Almost always, these claims are presented as facts, even though scientific validation is missing.

\section{Why was this study done?}

Popular media claims about personality are largely ignored by personality science, and unfortunately, the popular media in turn often ignores personality science! We sought a creative but systematic way to turn rather poetic and sometimes vague personality claims on popular websites into testable predictions, and then to test them empirically. The goals of the study were three: 1) to create a more direct dialogue between popular media claims and personality science; 2 ) to refine and propose a lexical methodology that can be used to test this as well as other popular-culture claims about personality; and 3) to inform colour researchers and the public about whether there is any truth to colour preferences predicting personality traits. 


\section{What did the researchers do and find?}

We assessed popular media claims in two stages. In the first stage, we catalogued specific statements of what colour preferences are purported to indicate about personality from six popular websites, including those in English, French, and German. The extracted personality descriptions were then matched to lists of key terms that have been found across many languages to define the core of six broad personality traits. These six traits, from the Big Six/HEXACO models, encompass the "Big Five", the most commonly used personality traits in personality science (Extraversion, Conscientiousness, Agreeableness, Emotional Stability [also called Neuroticism], and Openness/Originality), and add a sixth domain of honesty and morality content (Honesty). This process led us to identify 11 specific and systematic predictions for colour-personality relationships. For instance, the websites predicted higher Extraversion among those whose favourite colour is red, orange, yellow, pink, or turquoise.

In the second stage, we tested these 11 testable predictions against observed associations between Big Six trait scores and reports of favourite and least favourite colours by collecting data from 323 French-speaking participants (52 men). In an open-ended format, participants wrote in their favourite and least favourite colours. This allowed for a lot of individuality - 104 different favourite shades and 82 least favourite! These included dark raspberry, lime green, and indigo for favourites, and goose poop green and mouse grey for least favourites. A few shades, like lilac, bright green, mustard yellow, khaki, and fuchsia, were named as favourites by some participants but least favourite by others, showing the diversity in individual colour preferences.

The participants then self-categorised their choices into 13 predefined categories, including the 11 basic colour terms in French, plus yellow-green and turquoise. There, dark raspberry was self-categorised as "red", fuchsia as "pink", goose poop green as "yellow-green" or "green", depending on the participant. For every prediction (e.g., red and extraversion), we compared scores on the relevant personality trait (e.g., extraversion) between participants who chose or did not choose the predicted favourite colour (e.g., red). We failed to confirm any of the 11 predictions. Further exploratory analyses revealed no reliable associations between any colour preferences and any personality traits.

\section{What do these findings mean?}

Our findings indicate that favourite colours are unrelated to personality, at least as captured by reliable and valid trait models, the Big Five and the Big Six/HEXACO models. Future studies might explore how our colour choices impact the way others perceive us, but for the moment, the best evidence is that whatever colours you love, and whatever they might indicate about your tastes, preferences, and prior associations, they do not reveal anything systematic about your typical patterns of behaviour and feelings. 


\section{Relevance Statement}

Popular channels and professionally used personality tests convey claims that favourite colours reveal personality. This study uses lexical and empirical methods to identify and test such claims and shows that they do not. We provide a model for testing other popular claims about personality.

\section{Key Insights}

- Popular media websites claim that favourite colours indicate one's personality.

- We were able to identify 11 testable personality-colour predictions.

- We tested these predictions against Big Six questionnaire data.

- Favourite colours did not predict Big Six personality traits.

History includes many creative attempts to reveal hidden character and personality traits. These can range from the analysis of handwriting, to the shape and ridges of the skull, to the arrangement of stars and planets at a person's time of birth. While some of these approaches have been discredited and fallen into disuse, others are billion-dollar industries ${ }^{1}$, providing a parallel to the scientific work of personality psychology, and are often better known to the public. While personality researchers have other scientific and applied priorities, we believe that applying creative empirical methods to addressing this parallel domain of personality assessment could contribute to society. It provides concrete evidence for the utility or the lack thereof for popular 'parallel' models. Thus, the current study uses lexical and empirical methods to identify and test such claims with regard to colour preferences. This domain is of interest due to its prevalence on popular media, its financial profile, and because the question is also of relevance to colour psychologists, who study how colour contributes to social interactions and human behaviour (Elliot \& Maier, 2014; Palmer et al., 2013).

The sensory experience of colour seems so convincing that corporations pay for colour-based personality tests to select future employees ${ }^{2}$. Colour is assumed to convey comprehensive messages about oneself and others. For example, one can read that those who love red are "extroverted and optimistic, confident and courageous" while those who love blue are "conservative, reliable and trustworthy" (Scott-Kemmis, 2018). Another example reads that those who prefer red are "fiery and energetic" and have a "strong personality" while those who prefer blue are the "meditative type, ... good at keeping calm and level-headed" (McArthur, 2017). These examples demonstrate that such colour-personality claims are presented as facts, although scientific validation is missing.

\footnotetext{
1) https://www.newyorker.com/magazine/2019/10/28/astrology-in-the-age-of-uncertainty

2) See some examples here: https://www.testgroup.nl/en/4-colour-test-the-bridge-personality-colour/ and https:// www.colorcode.com/
} 
In the scientific literature, we can distinguish between two major types of commercially available colour-based personality tests. In the first type of tests (e.g., Lüscher, 1969), participants rank pre-selected colours by preference and this ranking supposedly describes personality traits and people's motivations. If darker colours are ranked more highly, participants should have more psychological issues. However, the test by Lüscher showed low construct validity (e.g., French \& Alexander, 1972). The second type of tests (e.g., Hartman, 1987) uses participants' responses to a particular personality questionnaire to attribute them to one of usually four colour groups. The groups represent different personalities and motivational styles. For instance, people in the "red" group are motivated by power and "generally are responsible, decisive, proactive and assertive". Those in the "blue" group are motivated by intimacy and "are generally loyal, sincere, and thoughtful" (Color Code LCC, 2021). Hartman's test weakly correlated with scientifically validated objective personality tests, showing low construct validity (Ault \& Barney, 2007). Both types of tests belong to so-called projective personality tests requiring a substantial degree of interpretation. Unfortunately, while rarely reliable, such tests are popular among non-scientific communities (Sartori, 2010), and in applied domains, often generating high profits.

Beyond such tests, a few prior studies have tested the associations between colours and more established personality trait measures (Bakker et al., 2015; Bimler et al., 2014; Cigić \& Bugarski, 2010; He et al., 2011; Lange \& Rentfrow, 2007; Pazda \& Thorstenson, 2018; Rosenbloom, 2006). Only two of these, however, directly tested the validity of colour-personality relationships (Bimler et al., 2014; He et al., 2011). Bimler and colleagues (2014) had participants complete a validated Big Five personality questionnaire (International Personality Item Pool) and assessed their colour preferences with a forced-choice paradigm, meaning, in each trial, participants chose their favourite colour patch from three alternatives. They found that higher Openness scores correlated with lower preference for blue and higher preference for red and pink. Higher Neuroticism scores correlated with lower preference for blue and higher preference for red and purple. Finally, higher Agreeableness scores correlated with higher preference for green and lower preference for pink and purple. In another study, participants completed Zuckerman and Kuhlman's Alternative Five questionnaire and ranked their preferences for 11 colour patches, corresponding to the 11 basic colour terms (He et al., 2011). Here, higher Sociability, Neuroticism-Anxiety, and Aggression-Hostility scores correlated, respectively, with lower preference for yellow, higher preference for grey, and lower preference for orange.

It is challenging to link such empirical findings to claims in the popular media and projective tests for at least three reasons. First, such claims are numerous and diverse, and not based on the outcomes of the scarce empirical studies. Second, such claims deal mainly with favourite colours (i.e., absolute colour preferences). In contrast, the empirical studies assessed only relative preferences on pre-selected colours, rather than 
absolute preferences. Third, "personality" descriptions in such claims are often vivid but hard to operationalize. For example, one website describes red lovers as "action oriented with a deep need for physical fulfilment and to experience life through the five senses" (Scott-Kemmis, 2018). The same website described purple lovers as "gentle and free spirit, [whose] feelings run deep and [who] can be quite sensitive to hurtful comments from others, although [they] would never show it." Trying to identify relevant personality traits in these descriptions and relate them to validated personality models like the Big Five and the Big Six is challenging and somewhat subjective.

In the current study, we tested the validity of claims that colour preferences predict one's personality in two stages. In the first stage, we catalogued specific favourite colour/personality claims made on six websites in three languages. We focused on websites because of their widespread availability. Using a lexical approach, we then linked these claims to specific Big Six/HEXACO traits using published lists of the key traits in these models (Ashton et al., 2004; Ashton \& Lee, 2007; Saucier, 2009). Finally, we selected claims that systematically appeared on the majority of the websites. In the second stage, a sample of French-speaking participants named their favourite and least favourite colours and categorised their spontaneous choices into 13 predefined categories. Participants also completed the 30QB6 Big Six personality inventory (Thalmayer \& Saucier, 2014; see also Supplementary Materials). We used these empirical data to statistically test the validity of the determined claims, and to explore for potential other colour-personality-trait relationships.

\section{Stage 1: Determination of Website Claims}

\section{Compilation of Websites}

We selected psychology websites in four steps. In the first step, we profited from our multilingual research team by selecting sites in English, French, and German that described how favourite colour indicates personality traits. In Google, we used the search terms "personality" and "colour". We retained a website for analysis if it explicitly 1) used favourite colours as categories, 2) included many of our pre-defined colour categories (see "Colour Preferences" in section "Stage 2: Validation of Website's Claims") as opposed to only four colours (e.g., red, yellow, green, blue), 3) linked colours to personality characteristics, 4) provided reasonably detailed personality descriptions, and 5) did not use highly similar wording as another website we had already selected.

We did not aim to compile all possible colour-personality websites but aimed for a representative selection of independent websites to determine common colour-personality claims circulating the Internet. We captured the information at the moment of data extraction in March 2020 using screenshots (available in Supplementary Materials). Our search strategy and criteria led us to choosing the following six websites: 
1. Empower yourself (in English, https://www.empower-yourself-with-colorpsychology.com/personality-color.html, henceforth referred to as EN1)

2. Sweety high (EN2, in English, https://www.sweetyhigh.com/read/favorite-colorpersonality-052917)

3. Louise Myers (EN3, in English, https://louisem.com/60206/favorite-color-sayinfographic)

4. Santé plus (FR1, in French, https://www.santeplusmag.com/votre-couleur-prefereeen-dit-long-sur-votre-personnalite/)

5. Terra Femina (FR2, in French, https://www.terrafemina.com/forme/bien-etre-beaute/ articles/54484-ce-que-votre-couleur-preferee-revele-de-votre-personnalite.html)

6. Idee für mich (DE1, in German, https://www.idee-fuer-mich.de/bekennen-sie-farbewas-ihre-lieblingsfarbe-ueber-ihre-persoenlichkeit-aussagt-980.html)

\section{Lexical Analysis of Personality Descriptors}

In the second step, we extracted the terms used to describe personality expressions from each website, separately for each colour (see Table S1 for English terms and Table S2 for French and German terms in Supplementary Materials). For the French and German websites, we extracted terms in the original language and then translated them into English, using the relevant Cambridge Dictionary (e.g., https://dictionary.cambridge.org/dictionary/german-english/). When a dictionary translation was unavailable or the phrase contained more than two words, we instead relied on DeepL translator (https://www.deepl.com/en/translator). Our research team included native speakers of all three languages, and bilingual speakers of every pair of languages, allowing for ample cross-checking and discussion of the formally derived translations.

In the third step, we matched the personality terms extracted from these websites with the lists of adjectives that define the cross-cultural core of each Big Six personality trait as determined from previous lexical studies. We used three sources: 1) The relatively narrow selection of adjectives used to define the HEXACO model (Ashton et al., 2004); 2) the broader selection of adjectives that led to the Questionnaire Big Six inventories (Saucier, 2009); and 3) the list of key terms for the HEXACO inventory (Ashton \& Lee, 2007). We counted the instances that personality terms from the websites matched to this combined list of Big Six personality terms (see Table S3 in Supplementary Materials). The counts of matches for each website appear in Table S1 and Table S2 (see Supplementary Materials).

\section{Systematic Website Predictions}

In the fourth step, we assessed for convergence of claims across the websites to define testable predictions. We counted the number of websites that associated each colour with each Big Six personality dimension. A website was counted irrespective of how many 
personality terms matched the terms in the combined list (i.e., one match was enough). We deemed an association convergent across sites if the majority of the websites made the same association (i.e., associated the same colour with the same Big Six trait).

Accordingly, we formulated testable predictions for red, orange, yellow, green, blue, purple, white, and black. Here, four out of six websites endorsed the same colour-personality associations. In the cases of pink, brown, and grey, we had information from only five websites. Accordingly, we formulated testable predictions when three out of five websites endorsed the same colour-personality associations. For turquoise, we had information from only two websites and kept testable predications when one out of two endorsed a colour-personality association. We were unable to formulate testable predictions for yellow-green because this colour was never mentioned on the websites. The count of websites making each prediction is presented in Table S4 (see Supplementary Materials) and the initial list of predictions is presented in Table 1.

\section{Table 1}

Systematic Predictions Extracted From the Websites

\begin{tabular}{|c|c|c|c|c|}
\hline Colour & Big Six personality trait & Matching term & Direction & Included/Excluded \\
\hline Red & Extraversion & $\begin{array}{l}\text { Active (2), extraverted (2) and } \\
\text { outgoing }\end{array}$ & Positive & Included \\
\hline Orange & Extraversion & $\begin{array}{l}\text { Cheerful, sociable (4), extraverted } \\
\text { (2), friendly (2), and lively }\end{array}$ & Positive & Included \\
\hline Yellow & Extraversion & $\begin{array}{l}\text { Cheerful (3), sociable, shy, and } \\
\text { talkative }\end{array}$ & Positive & Included \\
\hline Yellow-green & No prediction & No systematic matches & None & Excluded, no prediction \\
\hline Green & Agreeableness & $\begin{array}{l}\text { Kind, calm, generous, } \\
\text { understanding, anxious, peaceful, } \\
\text { patient, and gentle }\end{array}$ & Positive & Included \\
\hline Turquoise & Agreeableness & Flexible & Positive & Included \\
\hline Turquoise & Resilience & Emotional and stable & Contradictory & $\begin{array}{l}\text { Excluded, contradictory } \\
\text { predictions }\end{array}$ \\
\hline Turquoise & Extraversion & Friendly & Positive & Included \\
\hline Turquoise & Openness/Originality & Creative & Positive & Included \\
\hline Blue & Openness/Originality & $\begin{array}{l}\text { Intellectual, conservative ( } 3 \text {, } \\
\text { talented, and wise }\end{array}$ & Contradictory & $\begin{array}{l}\text { Excluded, contradictory } \\
\text { predictions }\end{array}$ \\
\hline Purple & No prediction & No systematic matches & & Excluded, no prediction \\
\hline Pink & Agreeableness & $\begin{array}{l}\text { Kind, generous, gentle, and easy- } \\
\text { going }\end{array}$ & Positive & Included \\
\hline Pink & Extraversion & Sociable, outgoing, and friendly (2) & Positive & Included \\
\hline Brown & Conscientiousness & $\begin{array}{l}\text { Industrious, diligent, responsible (2), } \\
\text { dutiful, thorough, and conscientious }\end{array}$ & Positive & $\begin{array}{l}\text { Excluded, count too } \\
\text { small }\end{array}$ \\
\hline Brown & Extraversion & Quiet and friendly (3) & Positive & $\begin{array}{l}\text { Excluded, count too } \\
\text { small }\end{array}$ \\
\hline White & Conscientiousness & $\begin{array}{l}\text { Careful, neat, organised (2), and } \\
\text { frivolous }\end{array}$ & Positive & Included \\
\hline White & Openness/Originality & $\begin{array}{l}\text { Clever, wise (2), not shallow, and } \\
\text { original }\end{array}$ & Positive & Included \\
\hline
\end{tabular}




\begin{tabular}{lllll}
\hline Colour & Big Six personality trait & Matching term & Direction & Included/Excluded \\
\hline Grey & Resilience & Stable (3) and unemotional & Positive & $\begin{array}{l}\text { Excluded, count too } \\
\text { small }\end{array}$ \\
Black & Openness/Originality & $\begin{array}{l}\text { Important, conservative, } \\
\text { conventional (2), and creative }\end{array}$ & Contradictory & $\begin{array}{l}\text { Excluded, contradictory } \\
\text { predictions }\end{array}$ \\
\hline
\end{tabular}

Note. In the column "Matching term", numbers refer to the number of websites that used each term in their descriptions; no number means a single mention. We analysed the systematic predictions marked as "Included" in the "Included/Excluded" column. Predictions marked as "Excluded, count too small" would be testable with a larger sample size.

We then eliminated six predictions for practical reasons (see Table 1, column Included/Excluded). Three predictions, relating to brown or grey, were removed from further analyses, because fewer than 10 participants chose these as their favourite colour, leading to sample sizes too low to test the hypotheses. We eliminated three other predictions because the websites hypothesised opposite relationships for the same personality trait and colour. For example, four websites hypothesised a link between blue and Openness/Originality. But two of these predicted lower Openness/Originality (i.e., "conservative"), one higher ("wise"), and one both ("conservative", "intellectual", "talented") for people who love blue. After this exclusion procedure, we arrived at 11 testable predictions, summarised in Table 1.

\section{Stage 2: Validation of Website Claims}

\section{Participants}

Our sample included 341 (56 men) first-year psychology students with a mean age of 20.19 years (range 17-30, $S D=2.06$ ). All participants lived in Switzerland and the majority $(82 \%)$ were native speakers of French. All participants, irrespective of their native language, reported being fluent in French on a 1-8 Likert-type scale, where eight indicated complete fluency $(M=6.26, S D=0.81)$.

We aimed to include at least 84 participants for the MANOVA tests to achieve a power of 0.80 (WebPower R package; Zhang \& Mai, 2018), assuming a medium effect size $(r=.40)$, based on an earlier study (Bimler et al., 2014). We recruited participants taking part in the introductory course on Methods in Experimental Psychology. All volunteers were remunerated with course credit. Having fixed a recruitment period (October 2019), we tested every volunteer, surpassing our minimum sample size. Our sample size was larger than in most (Bimler et al., 2014; Jeon et al., 2020; Palmer \& Schloss, 2010) and comparable to a couple of other colour preference studies (He et al., 2011; Pazda \& Thorstenson, 2019). The study was conducted in accordance with the ethical principles expressed in the Declaration of Helsinki. No explicit ethical approval was obtained as it was not required by local law (Canton of Vaud). 


\section{Colour Preferences}

Participants named their favourite and least favourite colours in randomised order, each time in two steps. In the first step, participants typed the term for the colour they like the most or the least in an open answer format. In the second step, participants chose one of 13 predefined colour categories that best matched the colour they had written in: red, orange, yellow, yellow-green, green, turquoise, blue, purple, pink, brown, white, grey, and black (always appearing in this order). These categories included the 11 basic colour terms in French (Berlin \& Kay, 1969; Morgan, 1993). We added two additional colour categories, yellow-green and turquoise, as they have been found to be important in previous studies on colour preferences (Jonauskaite et al., 2016, 2019; Palmer \& Schloss, 2010). Throughout, we exclusively worked with colour terms; we did not show actual colours. This methodological choice is justified considering high similarity in colour-affect associations between terms and patches (Jonauskaite, Parraga, et al., 2020).

\section{Self-Report Personality Questionnaire}

The 30-item cross-cultural QB6 assesses six broad personality traits: Conscientiousness, Honesty, Agreeableness, Resilience, Extraversion, and Openness/Originality (Thalmayer \& Saucier, 2014). Each of the 30 items presents a statement (e.g., "I rarely worry") for which participants rate the degree of accuracy with which it describes themselves on a 5-point Likert-type scale. Fourteen items are reversely coded. Average scores and internal consistency values for our sample are presented in Table S5 (see Supplementary Materials). This model has close correspondences with the Big Five traits and the HEXACO model (Thalmayer et al., 2011), in addition to high cross-cultural applicability (Thalmayer \& Saucier, 2014). We obtained the French-language version from https://psychometriglossia.uoregon.edu/.

\section{Procedure}

We used the LimeSurvey platform (LimeSurvey Project Team, 2020) to collect data online in French. Participants started by reading information about the study and providing their informed consent to participate. We asked their age and gender, and their names for the purpose of providing course credit. The names were deleted before any data treatment or analysis. Participants then completed a colour-emotion association task, to be reported elsewhere. Relevant to this study, participants reported their favourite and least favourite colours in randomised order and completed the Big Six questionnaire. At the end of the study, participants reported further demographic information (colour

3) In French, rouge, orange, jaune, jaune-vert, vert, turquoise, bleu, violet, rose, brun, blanc, gris, noir. 
blindness, country of origin, country of residence, French fluency). Afterwards, they were thanked and debriefed. The entire study took about 15-20 minutes to complete.

\section{Data Preparation}

We excluded 12 potentially colour-blind participants. Three participants (one man) reported being colour-blind and nine participants (two men) were not sure if they were colour-blind. Furthermore, we excluded six participants (one man) who did not correctly categorise their favourite or least favourite colour (e.g., categorised "red" as "white", or "white" as "turquoise"). For analysis, we retained a final sample of 323 participants (52 men).

\section{Design and Statistical Analyses}

\section{Confirmatory Analysis}

Welch's $t$-tests were used to test each prediction (Table 1). We chose Welch's $t$-test instead of Student's due to our uneven sample sizes and confirmed normality by visual inspection. In every test, we compared scores of the relevant personality trait (e.g., Extraversion) between participants who indicated that the relevant colour (e.g., yellow) was their favourite colour and all participants who indicated that any other colour was their favourite (e.g., any but yellow). We used one-tailed tests since the predictions were directional. We controlled for multiple comparisons with False Discover Rate (FDR) correction for the $p$-values (Benjamini \& Hochberg, 1995).

\section{Exploratory Analysis}

We devised two analogous MANCOVA tests to assess whether colour preferences predicted any personality traits, irrespective of the predictions made on websites. We entered favourite colour in the first MANCOVA model as an independent variable, and least favourite colour in the second MANCOVA model. In these analyses, colour choices selected by fewer than 10 participants were grouped together into the category "other". For favourite colours, the category "other" included yellow-green, brown, and grey while for least favourite colours the category "other" included red, turquoise, blue, and white (see Table 2). As dependent variables, we included the six personality traits - Conscientiousness, Honesty, Agreeableness, Resilience, Extraversion, and Openness/Originality. As a covariate, we included sex (Bimler et al., 2014; He et al., 2011). We used deviation planned comparisons to interpret which favourite or least favourite colour, if any, predicted higher scores on any personality trait. These tests were two-tailed. 
Table 2

Frequencies in Counts and Percentages From Total Reported Favourite and Least Favourite Colours

\begin{tabular}{lcccc}
\hline & \multicolumn{2}{c}{ Favourite } & \multicolumn{2}{c}{ Least favourite } \\
\cline { 2 - 5 } Colour & Count & $\%$ & Count & \% \\
\hline Red & $49^{\mathrm{a}}$ & 15.2 & $8^{\mathrm{b}}$ & 2.5 \\
Orange & $14^{\mathrm{b}}$ & 4.3 & 31 & 9.6 \\
Yellow & 28 & 8.7 & 29 & 4.0 \\
Yellow-green & $3^{\mathrm{b}}$ & 0.9 & $14^{\mathrm{b}}$ & 13.6 \\
Green & 28 & 8.7 & $44^{\mathrm{a}}$ & 0.3 \\
Turquoise & 22 & 6.8 & $1^{\mathrm{b}}$ & 2.2 \\
Blue & $71^{\mathrm{a}}$ & 22.0 & $7^{\mathrm{b}}$ & 10.2 \\
Purple & 31 & 9.6 & 33 & 13.3 \\
Pink & 20 & 6.2 & $43^{\mathrm{a}}$ & 23.8 \\
Brown & $5^{\mathrm{b}}$ & 1.6 & $77^{\mathrm{a}}$ & 1.2 \\
White & $11^{\mathrm{b}}$ & 3.4 & $4^{\mathrm{b}}$ & 6.5 \\
Grey & $3^{\mathrm{b}}$ & 0.9 & 21 & 3.4 \\
Black & $38^{\mathrm{a}}$ & 11.8 & $11^{\mathrm{b}}$ & 323 \\
\hline Total & 323 & 100 & 300 \\
\hline
\end{tabular}

${ }^{a}$ Indicate over-represented colour choices for each predefined colour category. ${ }^{b}$ Indicate under-represented colour choices for each predefined colour category.

\section{Common to Both Analyses}

We supplemented both types of analyses with the calculation of the Bayes factor (Jarosz \& Wiley, 2014; Wagenmakers, 2007), using the Bayes Factor R package (Morey \& Rouder, 2018) and default priors of 0.707. The Bayes factor compared the fit of the data under the null hypothesis with the fit of the data under the alternative hypothesis. In case of the null results, the Bayes factor $\left(\mathrm{BF}_{01}\right)$ provided the likelihood that our data occurred under the null hypothesis relative to the likelihood under the alternative hypothesis. The $\mathrm{BF}_{10}$ (i.e., $1 / \mathrm{BF}_{01}$ ) provided the likelihood that our data occurred under the alternative hypothesis relative to the likelihood under the null hypothesis.

All statistical analyses were conducted in SPSS (Version 26) or R Studio (Version 1.3.1103) (R Version 4.0.3.; R Core Team, 2020). Alpha level was set to .05.

\section{Transparency, Openness, and Reproducibility}

We did not pre-register hypotheses or any other methods because we only extracted our hypotheses in Stage 1. Materials, data, and analysis scripts are available in Supplementary Materials. Note that we also collected colour associations with emotion concepts in the same testing session, which were not analysed here. 


\section{Results}

\section{Colour Preferences}

Participants named 104 specific shades of colours as their favourite and 82 as their least favourite in the open answer format (see Table S6 in Supplementary Materials). The colour terms named were quite varied, including dark raspberry, lime green, and indigo for favourite colours, and goose poop green, mouse grey, and aubergine for least favourite colours. A few shades, like lilac, bright green, mustard yellow, khaki, and fuchsia, were named as favourite by some participants but least favourite by others, showing the diversity in individual colour preferences. These examples are all non-basic colour terms, each of which can be more or less easily categorised into the 11 basic colour terms (for further reading on non-basic colour terms, see Biggam, 2012). Around half of the participants instead provided a basic colour term (e.g., red, green) in the open answer format, slightly more often for least favourite (66.2\%) as compared to favourite (46.7\%) colours (see frequencies for each colour category in Supplementary Materials, Table S6).

Next, participants self-categorised the colour terms they had named into 13 predefined categories. For instance, dark raspberry was self-categorised as "red", fuchsia as "pink", goose poop green as "yellow-green" or "green", khaki as "brown", "green" or "yellow-green", and so on (see Table S6 in Supplementary Materials).

Chi-square tests on predefined colour categories showed that favourite colours, $\chi^{2}(12)$ $=186.5, p<.001$, and least favourite colours, $\chi^{2}(12)=220.1, p<.001$, were not evenly distributed. Based on standardised residuals, favourite colours chosen more often than expected by chance were blue $(p<.001)$, red $(p<.001)$, and black $(p<.010)$ while favourite colours chosen less often than expected by chance were grey $(p<.001)$, yellow-green $(p<.001)$, brown $(p<.001)$, white $(p<.010)$, and orange $(p<.050$; see Table 2$)$. The least favourite colours chosen more often than expected by chance were brown $(p<.001)$, green $(p<.001)$, and pink $(p<.001)$ while least favourite colours chosen less often than expected by chance were turquoise $(p<.001)$, white $(p<.001)$, red $(p<.001)$, blue $(p$ $<.001)$, black $(p<.010)$, and yellow-green $(p<.050$; see Table 2$)$.

\section{Confirmatory Analysis of Personality Traits and Colour Preferences}

Welsch's $t$-tests compared the link between colour preferences and personality traits for each testable website prediction (Table 3). The tests supported none of the predictions, whether looking directly at the FDR corrected $p$-values $(.396-.988)$ or the Bayes factors. All but one of the predicted associations were more likely to occur under the null hypothesis relative to the alternative hypothesis, at a likelihood between 1.6 and 13.1 times (see $\mathrm{BF}_{01}$ in Table 3). The Bayes factors provided strong evidence in favour of the null hypothesis for two predictions $\left(\mathrm{BF}^{\prime} \mathrm{s}_{01}=[12.0-13.1]\right)$, substantial evidence in favour of the null hypothesis for six predictions $\left(\mathrm{BF}^{\prime} \mathrm{s}_{01}=[4.4-8.7]\right)$, and anecdotal evidence in 
favour of the null hypothesis for the remaining three predictions $\left(\mathrm{BF}^{\prime} \mathrm{s}_{01}=[0.7-2.1]\right.$; see Table 3).

\section{Exploratory Analysis of Personality Traits and Colour Preferences}

The MANCOVA with favourite colour category as a predictor of the Big Six personality traits and sex as a covariate showed a main effect for sex, Pillai's Trace value $=.10$, $F(6,306)=5.37, p<.001, \eta_{\mathrm{p}}^{2}=.095$. After controlling for sex, favourite colour was not a significant predictor of personality traits (all traits combined), Pillai's Trace value $=.21$, $F(60,1866)=1.14, p=.216, \eta_{\mathrm{p}}^{2}=.035$. When inspecting each personality trait separately, sex was a significant predictor of Resilience scores, $F(1,311)=20.39, p<.001, \eta_{\mathrm{p}}^{2}=.062$, and marginally significant of Agreeableness scores, $F(1,311)=3.70, p=.055, \eta_{\mathrm{p}}^{2}=.012$, but not of the other four trait scores, $F^{\prime} s(1,311) \leq 3.14, p^{\prime} s \geq .077, \eta_{\mathrm{p}}^{2}$ 's $\leq .010$. On average, men had higher Resilience scores $(M=14.3, S E M=0.44)$ than women $(M=11.7$, SEM $=0.23)$. Men had also higher Agreeableness scores $(M=17.4, S E M=0.52)$ than women $(M=15.9, S E M=0.27)$. After controlling for sex, favourite colour was not a significant predictor of any of the individual personality traits, $F^{\prime} s(10,311) \geq 1.65, p$ 's $\geq .093, \eta_{\mathrm{p}}^{2}$ s $\leq .050$.

The analogous MANCOVA with least favourite colour category as a predictor variable of the Big Six personality traits and sex as a covariate again showed a main effect of sex, Pillai's Trace value $=.09, F(6,307)=5.01, p<.001, \eta_{\mathrm{p}}^{2}=.089$. After controlling for sex, least favourite colour was not a significant predictor of personality traits (all traits combined), Pillai's Trace value $=.14, F(54,1872)=0.83, p=.806, \eta_{p}^{2}=.023$. When inspecting each personality traits separately, sex was a significant predictor of Resilience scores, $F(1,312)=21.10, p<.001, \eta_{\mathrm{p}}^{2}=.063$, and Agreeableness scores, $F(1,312)=4.64$, $p=.032, \eta_{\mathrm{p}}^{2}=.015$, but not the other four personality trait scores, $F$ ' $s(1,312) \leq 2.35$, $p$ 's $\geq .127, \eta_{\mathrm{p}}^{2}$ 's $\leq .007$. The sex differences were analogue to those for most favourite colour. After controlling for sex, least favourite colour was not a significant predictor of any of the individual personality traits, $F^{\prime} s(9,312) \leq 1.53, p^{\prime} s \geq .135, \eta_{\mathrm{p}}^{2}$ s $\leq .042$.

Given the non-significant results, we calculated the non-directional Bayes factors on simplified models. We ran six analogous ANOVA models with favourite colour as a predictor and six ANOVA models with least favourite colour as a predictor. In each model, one of the Big Six personality traits was an outcome variable. In all models, the data were more likely to occur under the null hypothesis than the alternative hypothesis between 5.8 and 371 times $\left(\right.$ BF's $\left._{01}\right)$. We took this result as evidence against the alternative hypothesis and concluded that colour preferences and personality traits were not related. 


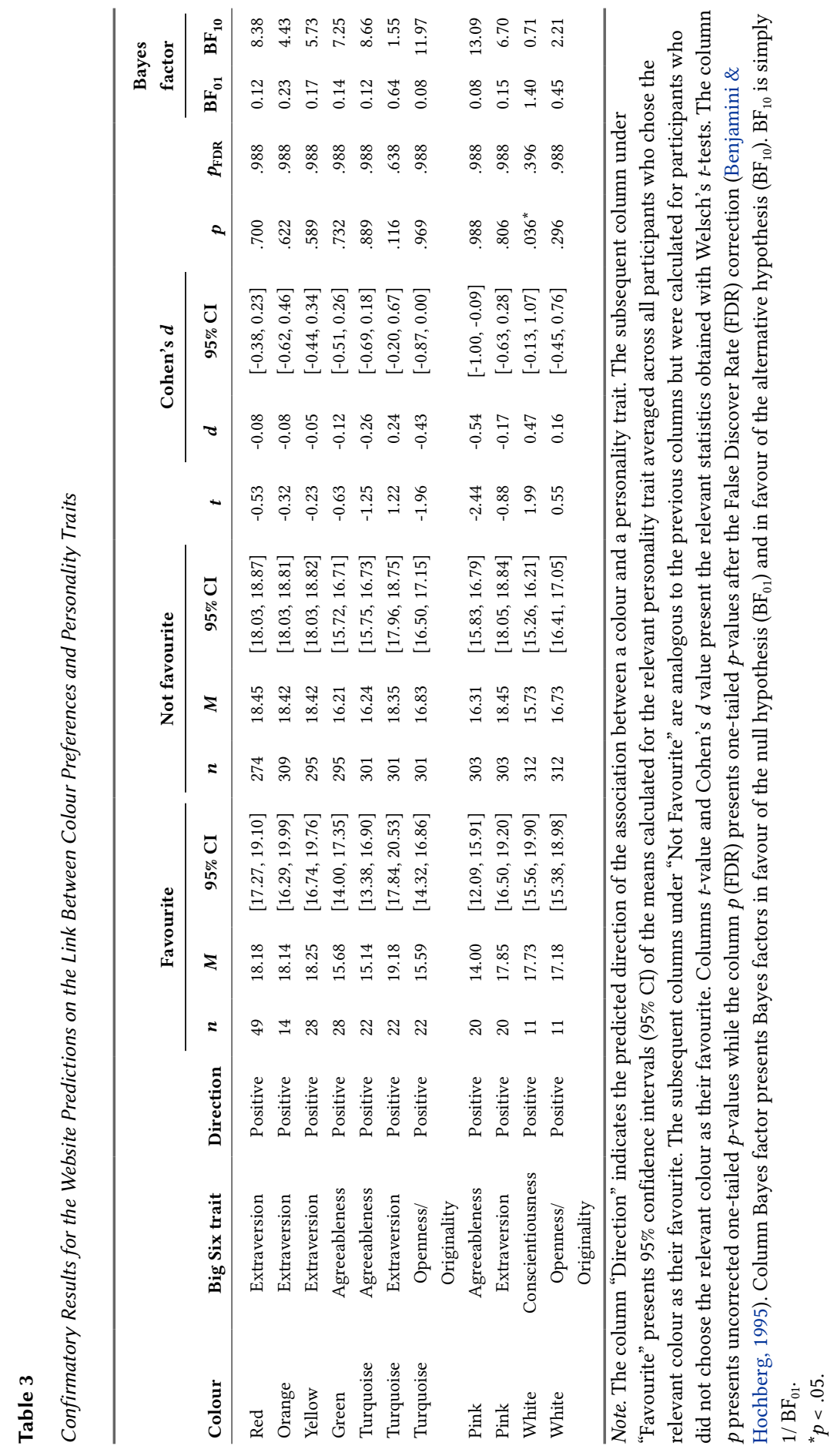




\section{Discussion}

The current study used lexical and empirical methods to identify and test a popular claim about personality inference, specifically based on colour preferences. Among many popular claims about what might reveal our true natures, this domain is of interest due to its prevalence on popular media and relevance to colour psychologists. According to claims in the popular media and widely used colour-based personality tests (Hartman, 1987; Lüscher, 1969; McArthur, 2017; Scott-Kemmis, 2018), one's favourite colours should reveal their personalities. While some prior studies have tested how colour preferences predict personality traits (Bimler et al., 2014; He et al., 2011), they were limited in matching the spontaneous popular claims with psychometrically defined traits. A translation between popular expressions and scientifically testable hypotheses is no doubt challenging.

Therefore, to bring evidence to such claims, we selected six representative websites. We extracted from them 11 specific and testable colour-personality predictions by matching popular expressions of personality to Big Six personality traits. We tested whether the predictions held true among participants' who reported their colour preferences and completed the Big Six personality questionnaire. Participants reported nearly 200 different shades of colour as their favourite or least favourite. After self-categorising these shades into 13 predefined colour categories and comparing colour preferences with personality traits, our results did not support any of the 11 testable predictions. The Bayes factors provided substantial to strong evidence in favour of the null hypothesis for the majority of the testable predictions. Overall, we conclude that our results speak against the notion that colour preferences reveal anything consistent about personality traits.

We have reasons to be convinced by this conclusion, thanks to a rigorous methodological approach. First, we asked participants to provide their favourite and least favourite colours, assessing their absolute colour preferences (see also, Jonauskaite et al., 2016) and not relative preferences, as in prior studies in this area (Bimler et al., 2014; He et al., 2011). The six popular media websites that we assessed specifically made references to absolute colour preferences. Second, we used a systematic method to match the descriptions from six representative websites to specific terms associated with personality traits across cultural contexts (Ashton et al., 2004; Ashton \& Lee, 2007; Saucier, 2009). Third, we included only coherent and consistent predictions drawn from the majority of the websites. Finally, we directly evaluated the predictions in behavioural data and using a cross-culturally validated Big Six personality trait questionnaire (Thalmayer et al., 2011; Thalmayer \& Saucier, 2014). 


\section{Challenges and Limitations}

We encountered some challenges in defining systematic predictions from popular media sources. First, colour-personality associations from such sources are almost always framed positively - liking a particular colour indicates good qualities, rarely are negative interpretations offered. These consistently positive descriptions suggest an unrealistic portrayal of a group of people, because personality trait scores generally follow a normal distribution (e.g., Funder, 2019). Roughly a similar number of people are expected to score high and low on each trait. But popular media sources restrict their predictions to only half of the dimension. If such websites would also consider the opposite side of a personality trait such as high Neuroticism, we might be able to find more meaningful colour-personality relationships. For instance, we might observe that high scores on Neuroticism are associated with preferences for darker colours, because such colours have been associated with negative emotions (Adams \& Osgood, 1973; Jonauskaite, Abu-Akel, et al., 2020) and negative moods (Carruthers et al., 2010; Jonauskaite et al., 2019). In fact, participants who preferred the concepts of darkness over lightness scored higher on Neuroticism and also reported more depressive and anxious symptoms (Persich et al., 2019). In such and other cases, relationships likely go well beyond perceivable colour features (hue, saturation, lightness), but are mediated through the metaphorical meanings of these features (see similar reasoning in Fetterman et al., 2015). Lightness and darkness are here most evident, because they denote positivity and negativity in very general terms.

Second, popular media descriptions seem narrow and vague when it comes to personality description. We found that these websites mainly mentioned qualities related to the traits of Extraversion, Agreeableness, and Openness/Originality. Furthermore, these traits were each linked to preferences for several colours. For instance, our websites predicted that anyone whose favourite colour was red, orange, yellow, pink, or turquoise should score high on Extraversion-related qualities. But if a large number of people should be extraverted, it is impossible to identify personality traits as a function of specific favourite colours. Put differently, personality descriptions on popular media are so general that they are likely to apply to everybody (Snyder et al., 1977).

Third, inferential statistics cannot be used to prove that a true effect is non-existent (Lakens et al., 2020). Inferential statistics ( $p$-values) can be used to reject the null hypothesis or demonstrate there is not enough evidence to reject the null hypothesis. Yet, in this study, we wanted to be able to accept the null hypothesis when needed. To this end, we calculated the Bayes factor which provided the strength of evidence in favour of the null hypothesis as well as in favour of the alternative hypothesis. The Bayes factor demonstrated with a substantial degree of certainty that most of the hypothesised associations between colour preferences and personality were unlikely to exist. 


\section{Future Directions}

While our results indicated a lack of systematic association for favourite colours in predicting Big Six personality traits, future work might discover other ways that colour choices indicate individual differences. Colour preferences in specific contexts, especially for clothing, might be driven by factors such as aesthetic preferences, hope to increase one's attractiveness, or perhaps motivations and identity (Lehmann et al., 2018; Yu et al., 2018). Future studies might also find that colour-personality associations exist for impressions of others, regardless of their actual traits. For example, a recent study demonstrated the implicit belief that one's clothing colours signal their personality (Pazda \& Thorstenson, 2019). These authors observed that unfamiliar individuals wearing more chromatic colours were judged as more extraverted and open to new experiences than individuals wearing less chromatic (i.e., greyish) colours.

Furthermore, our study offers an empirical approach to testing popular claims in the realm of personality. We provide a practical example on how popular claims can be extracted and systematised. We also showed how a lexical approach can be used to link popular and scientific terminologies. Such links are crucial to operationalize tests of the validity of personality claims. Considering that popular projective personality tests occupy an important niche in the corporate world, including both a significant financial outlay and influencing consequential decisions ${ }^{4}$, bringing scientific evidence to such claims is a meaningful benefit to society that personality psychologists are uniquely positioned to provide.

\section{Concluding Thoughts}

Popular media includes many bold claims about what might reveal our inner natures, one of which is the supposed link between colour preferences and personality characteristics. The consistency of such claims across the websites leaves an impression that colour-personality associations are well-established. However, after a systematic investigation into these claims and their validity, we found that colour preferences were unrelated to our participants' self-reported personality traits. We conclude that asking someone about their favourite colour is unlikely to provide much insight into their personality, contrary to popular beliefs, and thus lacks utility for wider application.

\footnotetext{
4) "Some experts estimate that as many as 60 percent of workers are now asked to take workplace assessments. The $\$ 500$-million-a-year industry has grown by about 10 percent annually in recent years. While many organizations use personality testing for career development, about 22 percent use it to evaluate job candidates, according to the results of a 2014 survey of 344 Society for Human Resource Management members." https://www.shrm.org/hr-today/news/hr-magazine/pages/0615-personality-tests.aspx
} 
Funding: This research was possible thanks to the support by the Swiss National Science Foundation, providing a Doc.CH and Postdoc.Mobility fellowship grants to DJ (P0LAP1_175055; P500PS_202956) and a project funding grant to CM (100014_182138).

Acknowledgments: The authors have no additional (i.e., non-financial) support to report.

Competing Interests: The authors have declared that no competing interests exist.

Author Contributions: Domicele fonauskaite-Idea, conceptualization | Design planning | Resource provision (materials, participants, etc.) | Research implementation (software, hardware, etc.) | Data collection | Data management (storage, curation, processing, etc.) | Visualization (data presentation, figures, etc.) | Data analysis | Validation, reproduction, checking | Writing | Feedback, revisions | Supervision, mentoring | Project coordination, administration | Funding to conduct the work. Amber Gayle Thalmayer-Idea, conceptualization | Design planning | Resource provision (materials, participants, etc.) | Validation, reproduction, checking | Writing | Feedback, revisions | Supervision, mentoring | Funding to conduct the work. Lauriane Müller-Design planning | Resource provision (materials, participants, etc.) | Data collection | Validation, reproduction, checking | Writing | Feedback, revisions. Christine Mohr-Idea, conceptualization | Design planning | Writing | Feedback, revisions | Supervision, mentoring | Project coordination, administration | Funding to conduct the work.

Ethics Statement: The study was conducted in accordance with the ethical principles expressed in the Declaration of Helsinki. No explicit ethical approval was obtained as it was not required by local law (Canton of Vaud).

Related Versions: No other previously published versions of this manuscript exist in part or in whole.

Data Availability: The data for this article are freely available (see the Supplementary Materials section).

\section{Supplementary Materials}

For this article the following Supplementary Materials are available (for access see Index of Supplementary Materials below).

Via PsychArchives repository:

- Open Peer-Review.

- Aggregated personality data used to test colour-personality predictions.

- Scripts to analyse the data as reported in the article.

- Supplementary Tables S1-S6.

Via University of Zurich website:

- $\quad$ QB6 questionnaires. 


\section{Index of Supplementary Materials}

Jonauskaite, D., Thalmayer, A. G., Müller, L., \& Mohr, C. (2021). Supplementary materials to: What does your favourite colour say about your personality? Not much [Data, Scripts, and Tables]. PsychOpen GOLD. https://doi.org/10.23668/psycharchives.5273

Personality Science. (Ed.). (2021). Supplementary materials to: What does your favourite colour say about your personality? Not much [Open peer-review]. PsychOpen GOLD. https://doi.org/10.23668/psycharchives.5274

Thalmayer, A. G. (2021). QB6 measures. psychology.uzh. https://www.psychology.uzh.ch/en/areas /sob/psyges/research/qb6.html

\section{References}

Adams, F. M., \& Osgood, C. E. (1973). A cross-cultural study of the affective meanings of color. Journal of Cross-Cultural Psychology, 4(2), 135-156. https://doi.org/10.1177/002202217300400201

Ashton, M. C., \& Lee, K. (2007). Empirical, theoretical, and practical advantages of the HEXACO model of personality structure. Personality and Social Psychology Review, 11(2), 150-166. https://doi.org/10.1177/1088868306294907

Ashton, M. C., Perugini, M., De Vries, R. E., Boies, K., Lee, K., Szarota, P., Di Blas, L., \& De Raad, B. (2004). A six-factor structure of personality-descriptive adjectives: Solutions from psycholexical studies in seven languages. fournal of Personality and Social Psychology, 86(2), 356-366. https://doi.org/10.1037/0022-3514.86.2.356

Ault, J. T., \& Barney, S. T. (2007). Construct validity and reliability of Hartman's Color Code Personality Profile: Information exchange article. International fournal of Selection and Assessment, 15(1), 72-81. https://doi.org/10.1111/j.1468-2389.2007.00369.x

Bakker, I., van der Voordt, T., Vink, P., de Boon, J., \& Bazley, C. (2015). Color preferences for different topics in connection to personal characteristics. Color Research and Application, 40(1), 62-71. https://doi.org/10.1002/col.21845

Benjamini, Y., \& Hochberg, Y. (1995). Controlling the false discovery rate: A practical and powerful approach to multiple testing. Journal of the Royal Statistical Society. Series B. Methodological, 57(1), 289-300. https://doi.org/10.1111/j.2517-6161.1995.tb02031.x

Berlin, B., \& Kay, P. (1969). Basic color terms: Their universality and evolution. University of California Press.

Biggam, C. P. (2012). Non-basic and non-standard colour expressions. In The semantics of colour: A historical approach (pp. 44-57). Cambridge University Press.

Bimler, D., Brunt, J., Lanning, L., \& Bonnardel, V. (2014). Personality and gender-schemata contributions to colour preferences. In W. Anderson, C. P. Biggam, C, Hough, \& C. Kay (Eds.), Colour studies: A broad spectrum (pp. 240-257). John Benjamins Publishing Company. https://doi.org/10.1075/z.191.16bim

Carruthers, H. R., Morris, J., Tarrier, N., \& Whorwell, P. J. (2010). The Manchester Color Wheel: Development of a novel way of identifying color choice and its validation in healthy, anxious 
and depressed individuals. BMC Medical Research Methodology, 10, Article 12.

https://doi.org/10.1186/1471-2288-10-12

Cigić, D., \& Bugarski, V. (2010). Personality traits and colour preferences. Curr Top Neurol Psychiatr Relat Discip., 18(4), 28-35.

Color Code LCC. (2021). About color code. Color Code Personality Science. https://www.colorcode.com/about/

Elliot, A. J., \& Maier, M. A. (2014). Color psychology: Effects of perceiving color on psychological functioning in humans. Annual Review of Psychology, 65(1), 95-120. https://doi.org/10.1146/annurev-psych-010213-115035

Fetterman, A. K., Liu, T., \& Robinson, M. D. (2015). Extending color psychology to the personality realm: Interpersonal hostility varies by red preferences and perceptual biases. Fournal of Personality, 83(1), 106-116. https://doi.org/10.1111/jopy.12087

French, C. A., \& Alexander, A. B. (1972). The Lüscher color test: An investigation of validity and underlying assumptions. fournal of Personality Assessment, 36(4), 361-365. https://doi.org/10.1080/00223891.1972.10119772

Funder, D. C. (2019). The personality puzzle (8th ed.). W. W. Norton \& Company.

Hartman, T. (1987). The color code. A new way to see yourself, your relationships and life. Color Code International.

He, W., Zhang, Y., Zhu, J., Xu, Y., Yu, W., Chen, W., Liu, Y., \& Wang, W. (2011). Could sex difference in color preference and its personality correlates fit into social theories? Let Chinese university students tell you. Personality and Individual Differences, 51(2), 154-159.

https://doi.org/10.1016/j.paid.2011.03.035

Jarosz, A. F., \& Wiley, J. (2014). What are the odds? A practical guide to computing and reporting Bayes Factors. The fournal of Problem Solving, 7(1), 2-9. https://doi.org/10.7771/1932-6246.1167

Jeon, E., Han, Y., \& Nam, M. (2020). How you see yourself influences your color preference: Effects of self-construal on evaluations of color combinations. Psychology and Marketing, 37(7), 980-994. https://doi.org/10.1002/mar.21348

Jonauskaite, D., Abu-Akel, A., Dael, N., Oberfeld, D., Abdel-Khalek, A. M., Al-Rasheed, A. S., Antonietti, J.-P., Bogushevskaya, V., Chamseddine, A., Chkonia, E., Corona, V., FonsecaPedrero, E., Griber, Y. A., Grimshaw, G., Hasan, A. A., Havelka, J., Hirnstein, M., Karlsson, B. S. A., Laurent, E., . . Mohr, C. (2020). Universal patterns in color-emotion associations are further shaped by linguistic and geographic proximity. Psychological Science, 31(10), 1245-1260. https://doi.org/10.1177/0956797620948810

Jonauskaite, D., Althaus, B., Dael, N., Dan-Glauser, E., \& Mohr, C. (2019). What color do you feel? Color choices are driven by mood. Color Research and Application, 44(2), 272-284. https://doi.org/10.1002/col.22327

Jonauskaite, D., Mohr, C., Antonietti, J.-P., Spiers, P. M., Althaus, B., Anil, S., \& Dael, N. (2016). Most and least preferred colours differ according to object context: New insights from an unrestricted colour range. PLOS ONE, 11(3), Article e0152194. https://doi.org/10.1371/journal.pone.0152194 
Jonauskaite, D., Parraga, C. A., Quiblier, M., \& Mohr, C. (2020). Feeling blue or seeing red? Similar patterns of emotion associations with colour patches and colour terms. i-Perception, 11(1), 1-24. https://doi.org/10.1177/2041669520902484

Lakens, D., McLatchie, N., Isager, P. M., Scheel, A. M., \& Dienes, Z. (2020). Improving inferences about null effects with Bayes Factors and equivalence tests. The fournals of Gerontology. Series B, Psychological Sciences and Social Sciences, 75(1), 45-57. https://doi.org/10.1093/geronb/gby065

Lange, R., \& Rentfrow, J. (2007). Color and personality: Strong's interest inventory and Cattell's 16PF. North American fournal of Psychology, 9(3), 423-438.

Lehmann, G. K., Elliot, A. J., \& Calin-Jageman, R. J. (2018). Meta-analysis of the effect of red on perceived attractiveness. Evolutionary Psychology, 16(4), 1-27. https://doi.org/10.1177/1474704918802412

LimeSurvey Project Team. (2020). LimeSurvey: An open source survey tool. LimeSurvey Project. http://www.limesurvey.org

Lüscher, M. (1969). The Lüscher color test. Random House.

McArthur, A. (2017). Here's what your favorite color reveals about your personality. Sweety High. https://www.sweetyhigh.com/read/favorite-color-personality-052917

Morey, R. D., \& Rouder, J. N. (2018). BayesFactor: Computation of Bayes factors for common designs (R package version 0.9.12-4.2). https://cran.r-project.org/package=BayesFactor

Morgan, G. (1993). Basic colour terms: Comparative results for French and Russian. Fournal of French Language Studies, 3(1), 1-17. https://doi.org/10.1017/S0959269500000326

Palmer, S. E., \& Schloss, K. B. (2010). An ecological valence theory of human color preference. Proceedings of the National Academy of Sciences of the United States of America, 107(19), 8877-8882. https://doi.org/10.1073/pnas.0906172107

Palmer, S. E., Schloss, K. B., \& Sammartino, J. (2013). Visual aesthetics and human preference. Annual Review of Psychology, 64, 77-107. https://doi.org/10.1146/annurev-psych-120710-100504

Pazda, A. D., \& Thorstenson, C. A. (2018). Extraversion predicts a preference for high-chroma colors. Personality and Individual Differences, 127, 133-138.

https://doi.org/10.1016/j.paid.2018.01.028

Pazda, A. D., \& Thorstenson, C. A. (2019). Color intensity increases perceived extraversion and openness for zero-acquaintance judgments. Personality and Individual Differences, 147(April), 118-127. https://doi.org/10.1016/j.paid.2019.04.022

Persich, M. R., Bair, J. L., Steinemann, B., Nelson, S., Fetterman, A. K., \& Robinson, M. D. (2019). Hello darkness my old friend: Preferences for darkness vary by neuroticism and co-occur with negative affect. Cognition and Emotion, 33(5), 885-900. https://doi.org/10.1080/02699931.2018.1504746

R Core Team. (2020). R: A language and environment for statistical computing: $R$ Foundation for statistical computing (Version 4.0.3.) [Computer software]. r-project. https://www.r-project.org/

Rosenbloom, T. (2006). Color preferences of high and low sensation seekers. Creativity Research fournal, 18(2), 229-235. https://doi.org/10.1207/s15326934crj1802_8 
Sartori, R. (2010). Face validity in personality tests: Psychometric instruments and projective techniques in comparison. Quality \& Quantity, 44(4), 749-759.

https://doi.org/10.1007/s11135-009-9224-0

Saucier, G. (2009). Recurrent personality dimensions in inclusive lexical studies: Indications for a Big Six Structure. fournal of Personality, 77(5), 1577-1614.

https://doi.org/10.1111/j.1467-6494.2009.00593.x

Scott-Kemmis, J. (2018). Your personality color. Empowered by Colour. http://www.empower-yourself-with-color-psychology.com/personality-color.html

Snyder, C. R., Shenkel, R. J., \& Lowery, C. R. (1977). Acceptance of personality interpretations: The "Barnum effect" and beyond. fournal of Consulting and Clinical Psychology, 45(1), 104-114. https://doi.org/10.1037/0022-006X.45.1.104

Thalmayer, A. G., \& Saucier, G. (2014). The questionnaire big six in 26 nations: Developing crossculturally applicable big six, big five and big two inventories. European fournal of Personality, 28(5), 482-496. https://doi.org/10.1002/per.1969

Thalmayer, A. G., Saucier, G., \& Eigenhuis, A. (2011). Comparative validity of brief to mediumlength Big Five and Big Six personality questionnaires. Psychological Assessment, 23(4), 995-1009. https://doi.org/10.1037/a0024165

Wagenmakers, E.-J. (2007). A practical solution to the pervasive problems ofp values. Psychonomic Bulletin \& Review, 14(5), 779-804. https://doi.org/10.3758/BF03194105

Yu, L., Westland, S., Li, Z., Pan, Q., Shin, M. J., \& Won, S. (2018). The role of individual colour preferences in consumer purchase decisions. Color Research and Application, 43(2), 258-267. https://doi.org/10.1002/col.22180

Zhang, Z., \& Mai, Y. (2018). WebPower: Basic and Advanced Statistical Power Analysis (R package version 0.5.2). https://CRAN.R-project.org/package=WebPower

\section{eapp}

Personality Science (PS) is an official journal of the European Association of Personality Psychology (EAPP).
(4) leibniz-psychology.org

PsychOpen GOLD is a publishing service by Leibniz Institute for Psychology (ZPID), Germany. 